Archives de sciences sociales des religions

176 | octobre-décembre 2016

Bulletin Bibliographique

\title{
Émile Poulat, postures et postérités
}

La rédaction

\section{OpenEdition}

Journals

Édition électronique

URL : http://journals.openedition.org/assr/28113

DOI : $10.4000 /$ assr. 28113

ISSN : $1777-5825$

Éditeur

Éditions de l'EHESS

Édition imprimée

Date de publication : 31 décembre 2016

Pagination : 13-14

ISSN : 0335-5985

\section{Référence électronique}

La rédaction, «Émile Poulat, postures et postérités 》, Archives de sciences sociales des religions [En ligne], 176 | octobre-décembre 2016, mis en ligne le 01 janvier 2017, consulté le 24 septembre 2020. URL : http://journals.openedition.org/assr/28113 ; DOI : https://doi.org/10.4000/assr.28113 


\section{L'atelier des sciences sociales du religieux}





\section{Émile Poulat, postures et postérités}

«Ce n'est jamais de bon cœur que j'ai consenti à faire des articles. Ils me paraissaient ne pas mériter le temps qu'ils exigent, et je leur préférais une œuvre de longue haleine, jalonnée de livres sérieux. Mais comment l'éviter quand on s'occupe d'une revue, quand on a des amis responsables de revues, quand on fréquente colloques et conférences ? [...] Rétrospectivement pourtant, le regard finit par en juger un peu autrement. [...] On découvre que s'est édifiée une ouvre involontaire ", reconnaissait Émile Poulat ${ }^{1}$. Michel de Certeau semble lui répondre: "Hommes de livres, nous sommes toujours portés à majorer l'influence des livres et à faire des indices littéraires qui nous restent du passé l'origine des expériences dont ils parlent. Dans bien des cas, c'est l'inverse qui est vrai : des échanges, des rencontres, une élaboration commune débouchent dans le livre ${ }^{2}$. » Qu'est-ce qui dans une œuvre fait sens? Quel cheminement, quels apports se dégagent qui inscrivent la production de toute une vie dans une réflexion plus large, à l'aune d'un champ en constante élaboration ?

Émile Poulat (1920-2014), récemment disparu, a joué un rôle essentiel au sein des sciences sociales des religions. Le comité des "Archives de Sciences Sociales des Religions" a souhaité que la revue mène une réflexion sur ses apports en donnant des coups de sonde à des moments, des débats, des questionnements qu'il a initiés ou auxquels il a participé. Le présent "Atelier » nous est apparu comme la chambre d'écho naturelle de cette réflexion. Ce dossier, coordonné par Frédéric Gugelot et Pierre Lassave, interroge la figure d'Émile Poulat comme intellectuel catholique et comme chercheur en sciences sociales. Il porte notamment sur l'entrée du témoin de l'expérience des prêtres-ouvriers dans la recherche scientifique (Tangi Cavalin), sur le fil qui relie cette expérience aux travaux du chercheur sur le modernisme (Giacomo Losito), sur sa critique des enquêtes sociographiques de pratique cultuelle conduites par le chanoine Fernand Boulard (Olivier Chatelan), sur la réception de ses thèses sur l'intransigeantisme catholique dans divers milieux d'historiens, de sociologues, et d'intellectuels proches de l'Église (Frédéric Gugelot), enfin sur les traits saillants des

1. Émile Poulat, Une Église ébranlée, Paris-Tournai, Casterman, 1980, p. 7.

2. Michel de Certeau, La Fable mystique, t. II, Paris, Gallimard, 2013, p. 172. 
derniers travaux sur la laïcité (Philippe Portier). Ce dernier texte est la transcription d'une intervention faite par l'auteur à l'Institut d'études avancées de Nantes où sont déposées désormais les fonds de bibliothèque et d'archives d'Émile Poulat ${ }^{3}$.

La rédaction

3. Table ronde publique du 22 novembre 2016 animée par Pierre Musso sur « Émile Poulat, laïcité et religions ", avec la participation de Jean-François Mayer, Philippe Portier, Andrea Riccardi et Yvon Tranvouez. Consultable sur : http://www.canal-u.tv/video/iea/table_ronde_ autour_d_emile_poulat_laicite_et_religions.25569. Sur le fonds Poulat en cours de classement à l'IEA de Nantes, voir nos informations sur le site de notre revue, rubrique "Archives du GSR », sous-rubrique « Émile Poulat » : <http://assr.revues.org/25698>. 